\title{
DEVELOPMENT AND STATISTICAL OPTIMIZATION OF GASTRORETANTIVE FLOATING MICROSPHERES OF PREGABALIN PREPARED BY W/0/0 MULTIPLE EMULSION METHOD
}

\author{
MONIKA KHARB $^{1^{*}}$, Y. S. TANWAR ${ }^{1}$
}

1Department of Pharmaceutics, Bhupal Nobles' College of Pharmacy, Faculty of Pharmacy, Bhupal Nobles' University, Udaipur, Rajasthan, India Email: mkharb.bn2017@gmail.com

Received: 21 Jan 2021, Revised and Accepted: 10 Mar 2021

\begin{abstract}
Objective: The aim of this study is to develop a gastroretentive microsphere of pregabalin using design of experiment (DoE) to decrease dosing frequency and increasing bioavailability.

Methods: Pregabalin microsphere was prepared by W/O/O multiple emulsion method using a mixture of ethyl cellulose (EC) and polyvinyl pyrrolidone (PVP) as rate-controlling polymer. Mixed solvent system comprising of dichloromethane (DCM) and acetonitrile (ACN) and light liquid paraffin was chosen as primary and secondary oil phase respectively. Taguchi design was employed for factor screening and Box Behnken design was used for the optimisation of critical process parameters.

Results: Taguchi design revealed that polymer: drug, DCM: ACN and PVP: EC is the critical factor for the preparation of microspheres. The optimized formulation was prepared using polymer: drug (4.95:1), DCM: ACN (53.76: 46.24) and PVP: EC (2:5) which showed mean particle size of $203.34 \pm 4.82 \mu \mathrm{m}$, practical yield of $87.52 \pm 2.91 \%$, encapsulation efficiency of $96.43 \pm 3.14 \%$, floating ability up to $90.42 \pm 1.64 \%$ and $\mathrm{T} 60 \%$ of 332.81 \pm 5.84 . Drug release from microsphere followed Higuchi Kinetic model.
\end{abstract}

Conclusion: In a nutshell, microspheres with excellent flowability and great encapsulation efficiency were successfully developed. These can be useful in improving patient compliance by reducing frequent dosing.

Keywords: Gastroretantive, Microsphere, Pregabalin, Multiple emulsion method, Optimisation, Box Behnken design, Taguchi design

(C) 2021 The Authors. Published by Innovare Academic Sciences Pvt Ltd. This is an open access article under the CC BY license (https://creativecommons.org/licenses/by/4.0/) DOI: https://dx.doi.org/10.22159/ijap.2021v13i3.41001. Journal homepage: https://innovareacademics.in/journals/index.php/ijap

\section{INTRODUCTION}

Oral drug delivery is the most commonly used route for drug administration because it has many advantages over other routes such as convenience, better patient compliance and flexibility in design of dosage form [1-3]. Over the past decades, oral controlledrelease (CR) formulation has evolved to prescription drug releases from dosage forms. But retaining the dosage form at the drug absorption site for a longer period of time is a challenge for conventional CR formulation, especially when the upper GIT is the absorption site.

Gastro retentive drug delivery systems (GRDDS) overcome this limitation of conventional CR formulation and increase residence time in Upper GIT. Prolong retention in the upper GIT leads to maximum drug release in the "drug absorption window". Thereby improving bioavailability [4]. Various approaches were used to develop GRDDS, including floating drug delivery, swellable drug delivery, bioadhesive drug delivery and high-density drug delivery $[5,6]$. Studies have found floating drug delivery systems (FDDS) to be the most appropriate of these approaches [7-10]. Multiple unit FDDS have gained more attention than single unit systems FDDS due to their properties such as uniform distribution throughout GIT, more reproducible absorption, lesser variability in GI transit time and reduced risk of local drug irritation [11-14].

The emulsification solvent evaporation method is very common among the methods used in the preparation of microspheres. Commonly used $\mathrm{O} / \mathrm{W}$ single emulsion method successfully encapsulates hydrophobic drugs, but the hydrophilic drug is not able to encapsulate in sufficient quantity with this method because the hydrophilic drug is rapidly diffused into the continuous phase. Therefore, double emulsion solvent evaporation method is being used for adequate encapsulation of hydrophilic drug. In several studies, W/O/W emulsification method has been used for the encapsulation of hydrophilic drugs, peptides, insulin and biopharmaceuticals $[15,16]$. In this method an aqueous solution of drugs is emulsified in to polymer solution in organic solvents to prepare a $\mathrm{W} 1 / 0$ emulsion. This $\mathrm{W} 1 / 0$ emulsion is then emulsified in the external aqueous phase containing emulsifying agent to prepare $\mathrm{W} 1 / 0 / \mathrm{W} 2$ emulsion. The organic volatile solvent evaporates and polymer forms a layer over the droplets. For high encapsulation efficiency, diffusion of the hydrophilic drug into the external phase is minimized by different approaches, such as by increasing viscosity of the external aqueous phase and using a stabilizer. Some studies have revealed that microspheres made from $\mathrm{W} / 0 / 0$ emulsion method in which continuous phase is also oil, have higher encapsulation efficiency than W/O/W emulsification method $[17,18]$. Because hydrophilic compounds cannot diffuse into the external phase since the oil is external processing medium.

Pregabalin (PGB), a gabapentinoid drug, is widely used in diabetic neuropathy, post-herpetic neuralgia, fibromyalgia and partial-onset seizures [19]. Pregabalin has not been absorbed equally by GIT. It mainly absorbs from the upper GIT. Pregabalin has a half-life short, whereby the conventional pregabalin capsule available in the market is administered two to three times a day. Therefore to reduce the dosing frequency of pregabalin need a gastroretantive controlled release system [20].

Systematic development of drug delivery systems using design of experiment (DoE) is an essential requirement of the current time [21]. In these techniques, the "best" formulation is chosen using lesser experiment, which saves time, effort and resources [22]. These techniques also helps in understanding the product and the process more thoroughly, leading to the development of a product with improved quality [23-25].

The goal of the present work, therefore, was to develop the gastro retentive microspheres of pregabalin using experiment designs for reducing dosing frequency. For this, $\mathrm{W} / 0 / 0$ emulsion method was used and a combination of ethyl cellulose and poly vinyl pyrrolidone was chosen as the carrier. In the first phase the influencing factors were evaluated using factor screening study and later the optimized gastro retentive microsphere of pregabalin was selected with the help of response surface methodology. 


\section{MATERIALS AND METHODS}

\section{Materials}

Pregabalin was received as a gift from M Sea Pharmaceuticals Pvt Ltd (Poanta Sahib; India). Ethylcellulose, cross link PVP and light liquid paraffin were procured from Himedia lab Ltd. (Mumbai; India). Dichloromethane (DCM), acetonitrile (ACN) and span 80 were purchased from Fisher Scientific (Mumbai; India). All other chemicals used were of analytical grade.

\section{Preparation of microspheres by $\mathrm{W} / 0 / 0$ multiple emulsion} method

EC and PVP were dissolved in a mixture of DCM and ACN. PGB was dissolved in water. Aqueous solution of PGB was added in to the polymer solution to prepare primary emulsion $(\mathrm{W} / 0)$. This primary emulsion was further added slowly in to light liquid paraffin containing Span 80 and stirred at $1000 \mathrm{rpm}$ for $2 \mathrm{hr}$ at $25^{\circ} \mathrm{C}$. The prepared microspheres were collected through filtration and washed repeatedly with water. The microcapsules were dried in a vacuum oven for $10 \mathrm{~h}$ at $30^{\circ} \mathrm{C}$ and stored in desiccators.

\section{Screening of influencing factors}

The Taguchi design was utilized for screening of factors [26, 3]. Seven factors were evaluated, i.e., polymer: drug, DCM: ACN, volume of aqueous phase $(\mathrm{ml})$, the volume of continuous phase $(\mathrm{ml})$, concentration of span $80(\%)$, rotation speed (rpm) and PVP: EC at their low and high levels (table 1). Particle size $(\mu \mathrm{m})$, encapsulation efficiency (EE \%) and time required for $60 \%$ drug release $\left(\mathrm{T}_{60 \%}\right.$, min) were the key CQAs studied thoroughly for selecting critical material attributes (CMAs) and critical process parameters (CPPs).

\section{Optimization of gastro retentive microsphere}

Systematic optimization of gastro retentive microsphere of pregabalin was done by Box-Behnken design (BBD) employing three critical factors, polymer: drug (X1); DCM: ACN (X2) and PVP: EC (X3), selected by factor screening study. Table 2 shows design matrix, composition of seventeen formulations in coded form and level of critical factors. A total seventeen gastroretantive microsphere formulations were prepared and evaluated for response variable such as particle size $(\mu \mathrm{m}), \mathrm{EE}(\%)$ and $\mathrm{T}_{60 \%}(\mathrm{~min})$. The second order quadratic models were applied to identify significant immediate interaction between studied critical factors. One-way analysis of variance (ANOVA) was employed to determine the significance of the model $(\mathrm{P}<0.05)$ and individual response. The residual plot and other parameters such as F-value, $\mathrm{P}$ value, regression coefficient $\left(\mathrm{R}^{2}\right)$ and the lack of fit were used to determine the good fit of the model. Response surface analysis was performed with the help of 3D-plots for thorough understanding of the effect of each CMA and/or CPP on the CQAs. Finally, the optimized formulation was selected from the numerical optimization based on the desirability function and the design space was also determined by graphical optimization.

\section{Characterization of gastroretantive microspheres}

\section{Practical yield of microsphere}

The collected dried microspheres were weighed and practical yield (PY, \%) was calculated by following formula:

$$
\mathrm{PY}(\%)=\frac{\mathrm{W}_{\mathrm{m}}}{\mathrm{W}_{\mathrm{E}}} \times 100(1)
$$

Where, $\mathrm{Wm}=$ Weight of microsphere, $\mathrm{W}_{\mathrm{E}}=$ Total weight of nonvolatile excipients

\section{Determination of particle size}

The particle size distribution of dried microsphere was determined employing a Malvern laser diffractometer (Mastersizer $2000 \mathrm{MS}$; Malvern Instruments, Worcestershire, UK) with a beam length of $2.40 \mathrm{~mm}$, range lens of $300 \mathrm{RF} \mathrm{mm}$, at $14.4 \%$ obscuration.

\section{Determination of encapsulation efficiency}

The accurately weight microsphere equivalent to $150 \mathrm{mg}$ of pregabalin were washed with distilled water to eliminate surface (unencapsulated) drug and then powdered in a mortar. The powder was transferred to a $50 \mathrm{ml}$ volumetric flask containing $0.1 \mathrm{~N} \mathrm{HCl}$ and flask was shacked for $24 \mathrm{hr}$. After $24 \mathrm{hr}$ solution was filtered and analysed employing ultraviolet spectroscopy at a $\lambda$ max of $242.5 \mathrm{~nm}$. The encapsulation efficiency (EE \%) or drug loading was calculated by the following formula $[27,28]$ :

$$
\mathrm{EE}(\%)=\frac{\mathrm{W}_{\mathrm{A}}}{\mathrm{W}_{\mathrm{t}}} \times 100(2)
$$

Where, $\mathrm{W}_{\mathrm{A}}=$ Actual loading of drug, $\mathrm{W}_{\mathrm{t}}=$ Theoretical loading of drug

\section{In vitro floating ability studies}

Floating ability of microsphere containing pregabalin was determined in the simulated gastric medium $(0.1 \mathrm{~N} \mathrm{HCl})$. Accurately weighed $50 \mathrm{mg}$ microspheres were dispersed over the surface of the dispersing medium (simulated gastric medium) kept in the USP type II dissolution test apparatus at $37{ }^{\circ} \mathrm{C}$. The medium containing microspheres was agitated by paddles at $100 \mathrm{rpm}$ for $12 \mathrm{~h}$. After 12 h, floating microspheres were collected, dried and weighed $[7,29]$. Percentage of floating microsphere was determined by using the following formula [7]:

$$
\text { Number of floating microsphere }(\%)=\frac{\mathrm{W}_{12}}{\mathrm{~W}_{0}} \times 100(3)
$$

\section{In vitro drug release study}

In vitro drug release study was performed in a USP dissolution apparatus (model-8000, Labindia Analytical Instruments Pvt. Ltd., Mumbai, INDIA) type I using $0.1 \mathrm{~N} \mathrm{HCl}$ as the dissolution medium to imitate gastric condition at $37 \pm 0.5^{\circ} \mathrm{C}$ and rotating at $100 \mathrm{rpm}$. The sample was withdrawn at predefined time intervals up to $12 \mathrm{~h}$ and replenished with an equal volume of fresh medium to maintain sink conditions. The sample was filtered through $0.45 \mu$ membrane filter and analysed using ultraviolet spectroscopy at a $\lambda$ max of $242.5 \mathrm{~nm}$ (Shimadzu UV-1800 UV-VIS spectrophotometer, Japan) after suitable dilution [27, 30, 31].

\section{Drug release kinetics study}

The drug release mechanism from optimise gastro retentive microsphere was established by fitting the release data to different kinetic models such Zero-order, First-order, Higuchi, Hixson-Crowell and Korsmeyer-Peppas model.

\section{Scanning electron microscopy}

Morphology of the optimize gastroretantive microsphere was determined using scanning electron microscopy (SEM) imaging analysis (JEOL, JSM-5200,Tokyo, Japan). The dried microsphere was kept on an aluminium holder and coated for 90s with gold in an argon atmosphere by Sputter Coater ${ }^{\circledR}$ JFC-1100 (JEOL, Tokyo, Japan) [29].

\section{RESULTS AND DISCUSSION}

Gastroretantive microsphere is a multiple unit drug delivery system and is the most efficient method of drug delivery as they are evenly distributed in the upper GIT resulting in a reproducible and efficient controlled drug release at the target site [11]. Multiple emulsion $\left(\mathrm{W} / \mathrm{O}_{1} / \mathrm{O}_{2}\right)$ evaporation diffusion method was used to prepare gastroretantive microspheres. In this method, internal aqueous phase and external oil phase separate with an oil phase. In this process an aqueous solution of PGB emulsified in a mixed solvent system (MSS) containing polymer (EC and PVP) to prepare primary emulsion $\left(\mathrm{W} / \mathrm{O}_{1}\right)$. This primary emulsion is then added to light liquid paraffin containing span $80(4 \%)$ to prepare $\mathrm{W} / \mathrm{O}_{1} / \mathrm{O}_{2}$ emulsion. The organic solvent was removed from the $\mathrm{W} / \mathrm{O}_{1} / \mathrm{O}_{2}$ emulsion by evaporation and extraction. The prepared microspheres were washed with $\mathrm{n}$-hexane to remove light liquid paraffin and $\mathrm{n}$-hexane also acted as solidifying agent for microspheres.

Because of the continuous phase oil, it is necessary that the solvent in which the polymer dissolves is immiscible with oil. All organic solvents such as alcohol, acetone, dimethyl sulfoxide, tetrahydrofuran are oil-immiscible and do not forms emulsion with oil. Only acetonitrile is a unique organic solvent that is polar, water- 
miscible and oil-immiscible. But the formation of the primary emulsion cannot be ensured due to water-miscibility of ACN, as the aqueous drug solution is added to the polymer solution the polymer will precipitate. Therefore a MSS was used for polymer solution in which DCM, a non-polar solvent, was mixed with ACN. Due to the oil miscibility of DCM, solvent removal also occurs by extraction in the continuous phase. After mixing the primary emulsion in the continuous phase, DCM undergoes rapid extraction in the oil phase and the polymer solution becomes viscous. This prevents migration of aqueous drug solution thereby increasing encapsulation efficiency [17].

\section{Screening of influencing factors}

Firstly, the screening of variables with high influence on CQAs was performed employing Taguchi design. Table 1 shows low and high value of studied factors. Pareto charts were used for quantitatively recognizing the influence of each studied factors on the selected CQAs for screening. The objective of the pareto chart is to screen the most influential factor(s) among a typical large set of factor variables [32]. Based on Pareto chart (fig. 1), polymer: drug, DCM: ACN and PVP: EC showed a distinctly significant effect on the CQAs, and

therefore, were selected as the critical factors for optimization of gastro retentive microsphere.

Table 1: Level of factors for factor screening study using taguchi design

\begin{tabular}{lll}
\hline Factors & Level & \\
\cline { 2 - 3 } & Low (-1) & High (+1) \\
\hline A: Polymer: drug & $1: 1$ & $5: 1$ \\
B: DCM: ACN & $30: 70$ & $70: 30$ \\
C: Vol. of aqueous phase & 1.0 & 3.0 \\
D: Vol. of continuous phase & 100 & 300 \\
E: Con. of span 80 & 0.5 & 2.0 \\
F: Rotation speed & 500 & 1500 \\
G: PVP: EC & $0: 1$ & $2: 5$ \\
CQAs & & \\
Y1= Particle Size $(\mu \mathrm{m})$ & & \\
Y2= Encapsulation efficiency $(\%)$ & & \\
Y3= Time for 60\% drug $\left(\mathrm{T}_{60 \%}\right)$ & & \\
\hline
\end{tabular}

ACN= Acetonitrile; $\mathrm{DCM}=$ Dichloromethane

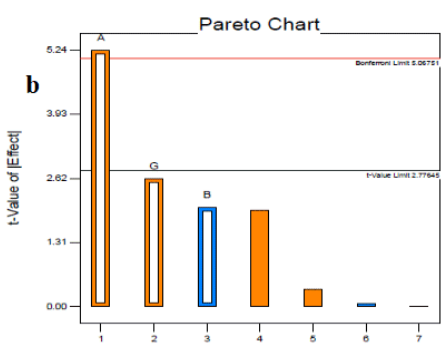

Rank

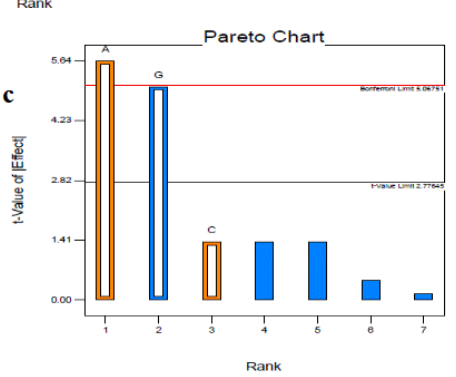

Fig. 1: Pareto chart depicting influence of process parameters on CQAs of gastro retentive microspheres (a) particle size (Y ${ }_{1}$ ), (b) EE (Y) and (c) $\mathrm{T}_{60 \%}\left(\mathrm{Y}_{3}\right)$

Table 2: Box-behnken design (BBD) matrix displaying seventeen formulations with varying levels of factors and result showing impact on CQAs

\begin{tabular}{|c|c|c|c|c|c|c|c|}
\hline Code & Run & $\mathrm{X1}$ & $\mathrm{X} 2$ & X3 & Y1* (mean \pm SD) & Y2* (mean \pm SD) & Y3* (mean \pm SD) \\
\hline MS1 & 1 & 0 & -1 & 1 & $123.98 \pm 2.23$ & $88.81 \pm 1.39$ & $328 \pm 5.62$ \\
\hline MS2 & 2 & 0 & -1 & -1 & $93.56 \pm 1.83$ & $78.16 \pm 1.63$ & $433 \pm 3.26$ \\
\hline MS3 & 3 & 0 & 1 & 1 & $215.32 \pm 2.93$ & $87.49 \pm 1.92$ & $317 \pm 2.43$ \\
\hline MS4 & 4 & -1 & 1 & 0 & $170.34 \pm 1.38$ & $72.09 \pm 2.65$ & $332 \pm 4.61$ \\
\hline MS5 & 5 & -1 & -1 & 0 & $95.67 \pm 3.82$ & $73.38 \pm 1.35$ & $342 \pm 3.24$ \\
\hline MS6 & 6 & 0 & 1 & -1 & $182.88 \pm 1.57$ & $77.92 \pm 1.79$ & $436 \pm 5.73$ \\
\hline MS7 & 7 & 1 & 0 & 1 & $187.40 \pm 3.82$ & $96.43 \pm 1.83$ & $340 \pm 1.53$ \\
\hline MS8 & 8 & 0 & 0 & 0 & $150.83 \pm 1.58$ & $83.48 \pm 1.62$ & $365 \pm 2.83$ \\
\hline MS9 & 9 & 0 & 0 & 0 & $145.63 \pm 2.72$ & $82.46 \pm 1.02$ & $370 \pm 2.46$ \\
\hline MS10 & 10 & 1 & 0 & -1 & $132.43 \pm 1.96$ & $85.21 \pm 1.11$ & $447 \pm 3.09$ \\
\hline MS11 & 11 & -1 & 0 & -1 & $126.53 \pm 0.93$ & $68.85 \pm 1.86$ & $399 \pm 4.32$ \\
\hline MS12 & 12 & 0 & 0 & 0 & $148.92 \pm 2.06$ & $82.67 \pm 2.19$ & $376 \pm 1.09$ \\
\hline MS13 & 13 & 0 & 0 & 0 & $146.21 \pm 1.53$ & $83.67 \pm 1.56$ & $368 \pm 3.25$ \\
\hline MS14 & 14 & 1 & -1 & 0 & $119.45 \pm 2.42$ & $90.32 \pm 1.21$ & $388 \pm 2.46$ \\
\hline MS15 & 15 & 1 & 1 & 0 & $222.51 \pm 1.28$ & $91.43 \pm 1.10$ & $392 \pm 4.05$ \\
\hline MS16 & 16 & -1 & 0 & 1 & $136.17 \pm 1.62$ & $78.62 \pm 2.17$ & $282 \pm 3.28$ \\
\hline MS17 & 17 & 0 & 0 & 0 & $142.61 \pm 2.24$ & $83.27 \pm 1.63$ & $373 \pm 4.82$ \\
\hline \multicolumn{5}{|c|}{ Factors } & -1 & 0 & +1 \\
\hline \multicolumn{5}{|c|}{ X1 = Polymer: drug } & $1: 1$ & $3: 1$ & $5: 1$ \\
\hline \multicolumn{5}{|c|}{ X2 = DCM: ACN } & $30: 70$ & $50: 50$ & $70: 30$ \\
\hline \multicolumn{5}{|c|}{ X3 = PVP: EC } & $0: 1$ & $1: 5$ & $2: 5$ \\
\hline
\end{tabular}

*Mean obtained from triplicate experiment $(n=3)$, Y1= Mean particle size $(\mu \mathrm{m}) \pm S D ; Y 2=$ Encapsulation efficiency $($ EE $\%)$; Y3=Time required to $60 \%$ drug release $(\mathrm{T} 60 \%, \mathrm{~h})$; ACN= Acetonitrile; DCM=Dichloromethane 
Table 3: Summary of ANOVA and other statistical parameters for the CQAs of gastroretantive microspheres of pregabalin

\begin{tabular}{|c|c|c|c|c|c|c|c|c|}
\hline Source & SS & Df & MSS & $\mathbf{F}$ & P value & Adj R ${ }^{2}$ & Pred R ${ }^{2}$ & Aedq preci \\
\hline \multicolumn{9}{|c|}{ Response Y1 (Particle size) } \\
\hline Model & 21215.17 & 9 & 2357.24 & 192.47 & $<0.0001$ & 0.9908 & 0.9627 & 47.248 \\
\hline Residual & 85.73 & 7 & 12.25 & - & - & - & - & - \\
\hline Lack of fit & 45.73 & 3 & 15.24 & 1.52 & 0.3378 & - & - & - \\
\hline Pure error & 40.00 & 4 & 10 & - & - & - & - & - \\
\hline Cor total & 21300.90 & 16 & & - & - & - & - & - \\
\hline \multicolumn{9}{|c|}{ Response Y2 (Encapsulation efficiency) } \\
\hline Model & 840.54 & 9 & 93.39 & 333.40 & $<0.0001$ & 0.9947 & 0.9815 & 68.768 \\
\hline Residual & 1.96 & 7 & 0.28 & - & - & - & - & - \\
\hline Lack of fit & 0.87 & 3 & 0.29 & 1.06 & 0.4588 & - & - & - \\
\hline Pure error & 1.09 & 4 & 0.27 & - & - & - & - & - \\
\hline Cor total & 842.50 & 16 & - & - & - & - & - & - \\
\hline \multicolumn{9}{|c|}{ Response Y3 $\left(\left(\mathrm{T}_{60 \%}\right)\right.$} \\
\hline Model & 31348.06 & 9 & 3483.12 & 330.83 & $<0.0001$ & 0.9946 & 0.9961 & 66.302 \\
\hline Residual & 73.70 & 7 & 10.53 & - & - & - & - & - \\
\hline Lack of fit & 0.50 & 3 & 0.17 & $9.10 \times 10^{-3}$ & 0.9986 & - & - & - \\
\hline Pure error & 73.20 & 4 & 18.30 & - & - & - & - & - \\
\hline Cor total & 31421.76 & 16 & - & - & - & - & - & - \\
\hline
\end{tabular}
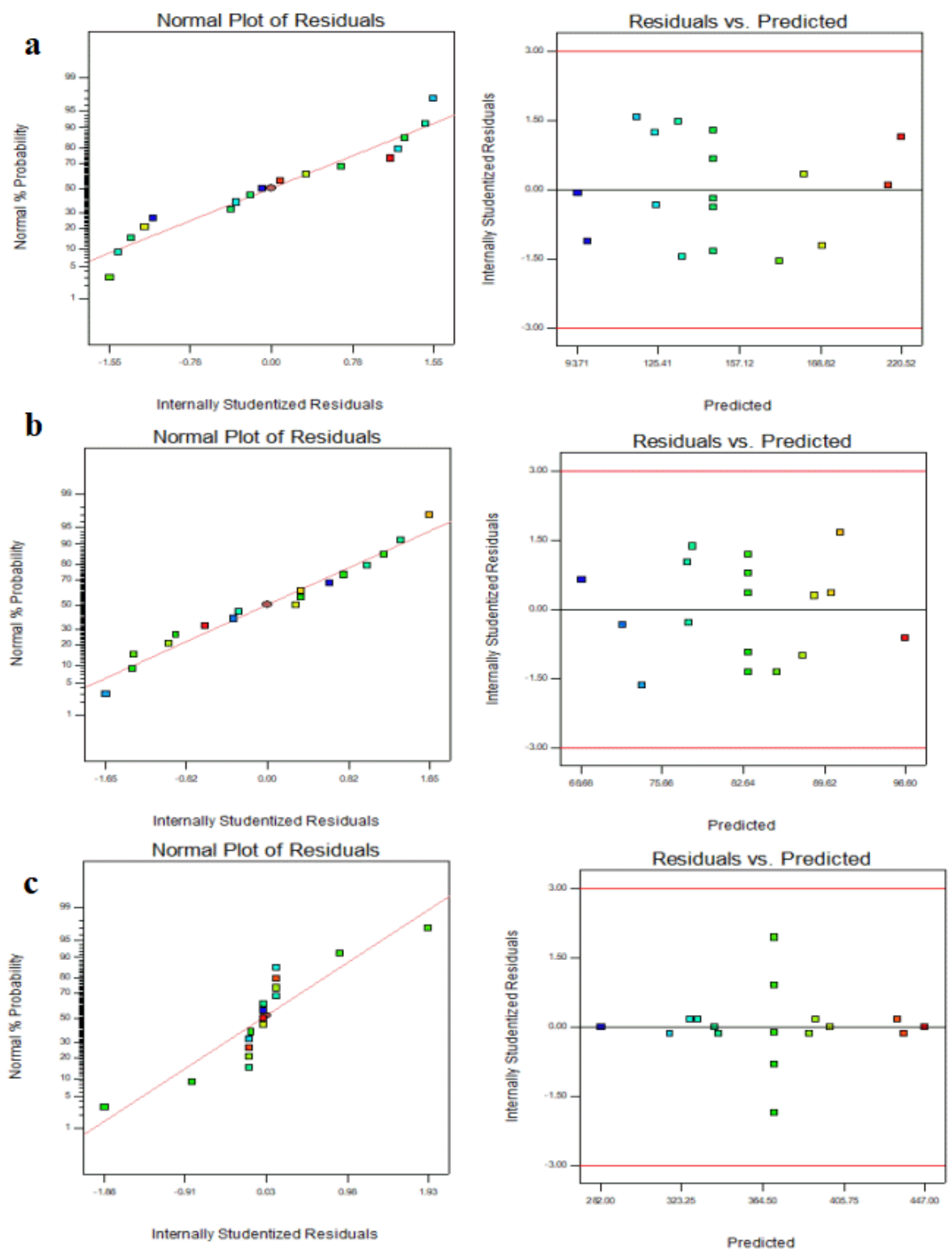

Fig. 2: Different residual plots depicting goodness of fit of model for (a) particle size $\left(\mathrm{Y}_{1}\right)$, (b) $E E\left(\mathrm{Y}_{2}\right)$ and (c) $\mathrm{T}_{60 \%}\left(\mathrm{Y}_{3}\right)$ 
Table 4: Coefficient and $p$-value of terms for the CQAs of gastro retentive microspheres of pregabalin

\begin{tabular}{|c|c|c|c|c|c|c|}
\hline \multirow[t]{2}{*}{ Factor } & \multicolumn{2}{|c|}{ Response Y1 } & \multicolumn{2}{|c|}{ Response Y2 } & \multicolumn{2}{|c|}{ Response Y3 } \\
\hline & Coefficient & P value & Coefficient & P value & Coefficient & P value \\
\hline $\mathrm{X} 1$ & 16.64 & $<0.0001$ & 8.81 & $<0.0001$ & 26.50 & $<0.0001$ \\
\hline $\mathrm{X} 2$ & 44.80 & $<0.0001$ & -0.22 & 0.2832 & -1.75 & 0.1710 \\
\hline X3 & 15.93 & $<0.0001$ & 5.15 & $<0.0001$ & -56.00 & $<0.0001$ \\
\hline X1X2 & 7.10 & 0.0048 & 0.60 & 0.0577 & 3.50 & 0.0679 \\
\hline X1X3 & 11.33 & 0.0003 & 0.36 & 0.2131 & 2.50 & 0.1672 \\
\hline $\mathrm{X}_{2} \mathrm{X} 3$ & 0.50 & 0.7812 & -0.27 & 0.3416 & -3.50 & 0.0679 \\
\hline $\mathrm{X}_{1}{ }^{2}$ & -1.57 & 0.3865 & -1.06 & 0.0045 & -9.20 & 0.0007 \\
\hline $\mathrm{X}_{2}{ }^{2}$ & 6.73 & 0.0056 & -0.24 & 0.3761 & 2.30 & 0.1891 \\
\hline $\mathrm{X}_{3}{ }^{2}$ & 0.37 & 0.8355 & 0.23 & 0.4046 & 5.80 & 0.0080 \\
\hline
\end{tabular}

Term indicated with Bold were insignificant $(\mathrm{p}>0.05)$

The mean particle size for all formulations was in the range $93.56 \pm 1.83-222.51 \pm 1.28 \mu \mathrm{m}$. The residual plot (fig. $2 \mathrm{a}$ ) for particle size depicted most of the coloured points representing values of particle size were situated around the normal probability line, which suggested that the observed value and predicted value of mean particle size were well fitted. The reduced polynomial equation for mean particle size in coded value was given below

$$
\begin{gathered}
\mathrm{Y}_{1}=+146.30+16.64 \mathrm{X}_{1}+44.80 \mathrm{X}_{2}+15.93 \mathrm{X}_{3}+7.10 \mathrm{X}_{1} \mathrm{X}_{2} \\
+11.33 \mathrm{X}_{1} \mathrm{X}_{3}+6.66 \mathrm{X}_{2}^{2}(4)
\end{gathered}
$$

The sign of coefficient (table 4) revealed that X1, X2 and X3 have a positive effect on the mean particle size. Similarly, interaction terms X1X2 and X1X3 have a positive effect on mean particle size.
Quadratic terms $\mathrm{X} 2^{2}$ were favorable for increasing particle size. The 3-D response surface graph (fig. 3a) shows the effect of critical factors on particle size. The value of the coefficient revealed that the proportion of DCM has the highest effect over the particle size. The particle size increased as proportion of DCM increased. It has been noted that after the DCM is extracted off. The viscosity of the solution decreases [18]. Viswanathan et al. also reported that the size of the particle increased as proportion of DCM increased because the viscosity of a polymer solution increased as soon as DCM was extracted off [17]. The particle size increase with an increase in the proportion of polymer and PVP. This may be due to increased viscosity of solution which results in decreased shearing efficiency $[33,34]$.
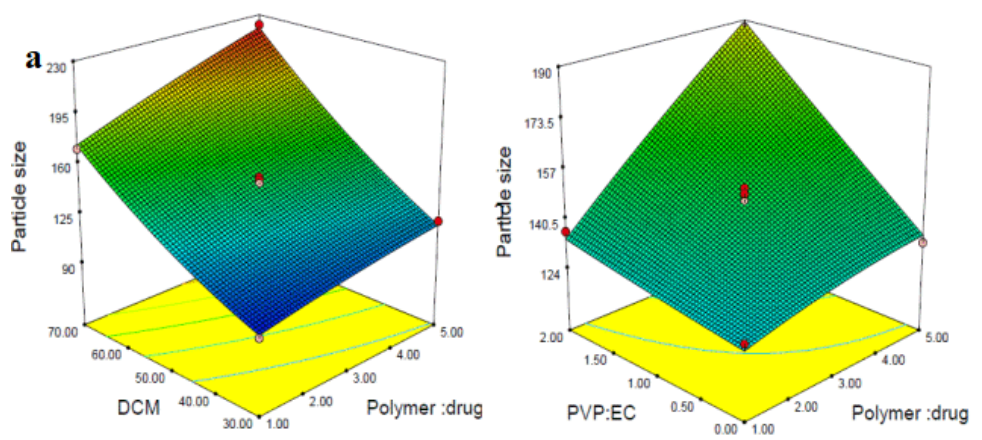

$\mathbf{b}$
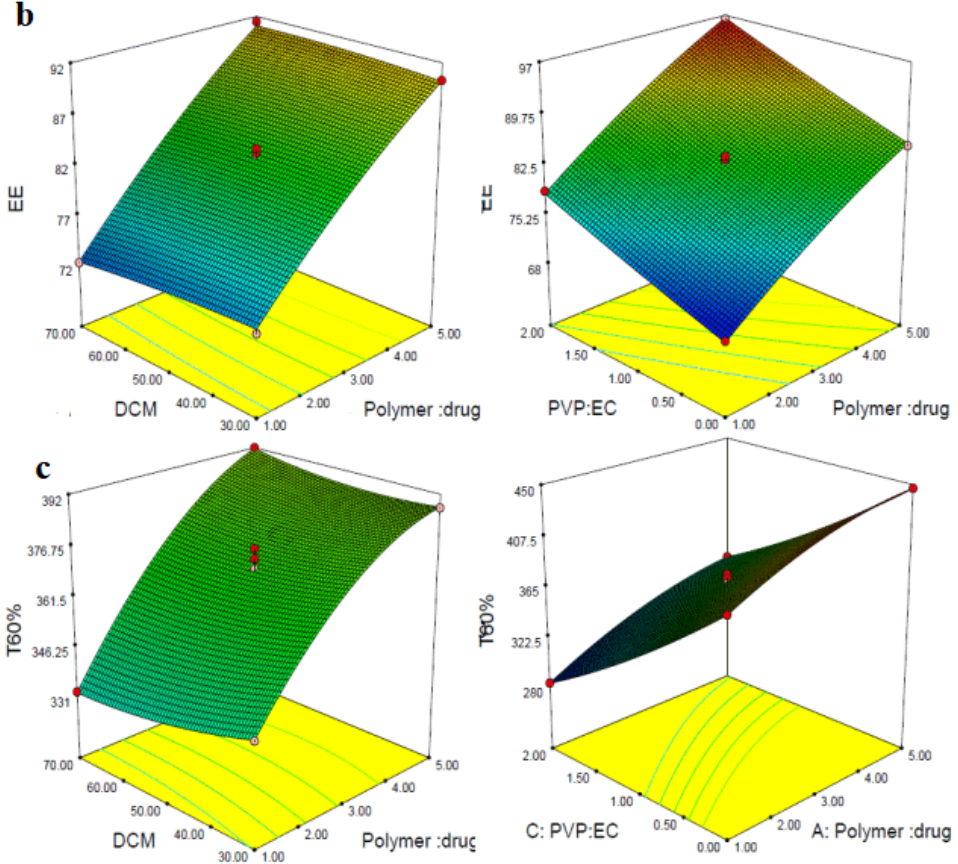

Fig. 3: 3D response surface plot depicting influence of critical parameters on CQAs of gastroretantive microspheres (a) particle size (Y), (b) EE ( $\left.Y_{2}\right)$ and (c) $\mathrm{T}_{60 \%}\left(\mathrm{Y}_{3}\right)$ 
The EE (\%) is an indicator of loading efficiency of drug and most important parameter for the development of microspheres. The EE (\%) of various microspheres was ranged from $68.85 \pm 1.86 \%-96.43 \pm 1.83 \%$. The residual plot of EE (fig. $2 \mathrm{~b}$ ) demonstrated goodness of fit of model. The p-value $<0.05$ of drug: polymer and PVP: EC indicated significant effect of on the EE, while DCM: ACN did not have a significant effect (pvalue $<0.05$ ) on $\mathrm{EE}$ (table 4). The effect of critical factors on $\mathrm{EE}$ is presented by reduced polynomial equation.

$$
\mathrm{Y}_{2}=+83.10+8.81 \mathrm{X}_{1}-0.22 \mathrm{X}_{2}+5.15 \mathrm{X}_{3}+0.60 \mathrm{X}_{1} \mathrm{X}_{2}-0.11 \mathrm{X}_{1}^{2}(5)
$$

The sign of coefficient displayed that ratio of polymer and ratio of PVP has a positive effect on EE. The influence of critical variables on $\mathrm{EE}$ is depicted by response surface plot (fig. $3 \mathrm{~b}$ ). The ratio of polymer has the highest effect on EE followed by the ratio of PVP. The EE increased with increase in the ratio of polymer and ratio of PVP indicating an improvement in the loading efficiency of the drug.

The $\mathrm{T} 60 \%$ of all formulation varied from $282 \pm 3.28-447 \pm 3.09 \mathrm{~min}$. Residual plot for goodness of model fit for T60\% is shown in fig. 2c. It was observed that $\mathrm{T} 60 \%$ was significantly $(\mathrm{P}<0.05)$ affected by the PVP: EC and polymer: drug (table 4). The effect of critical factors on T60\% was presented as the reduced quadratic model equation as below.

$$
\mathrm{Y}_{3}=+371.37+26.50 \mathrm{X}_{1}-56.00 \mathrm{X}_{3}-9.08 \mathrm{X}_{1}^{2}+5.92 \mathrm{X}_{3}^{2}(6)
$$

Ratio of polymer had a positive effect whereas the ratio of PVP had a negative effect on $\mathrm{T} 60 \%$. This is illustrated in the contour plot (fig. 3c).

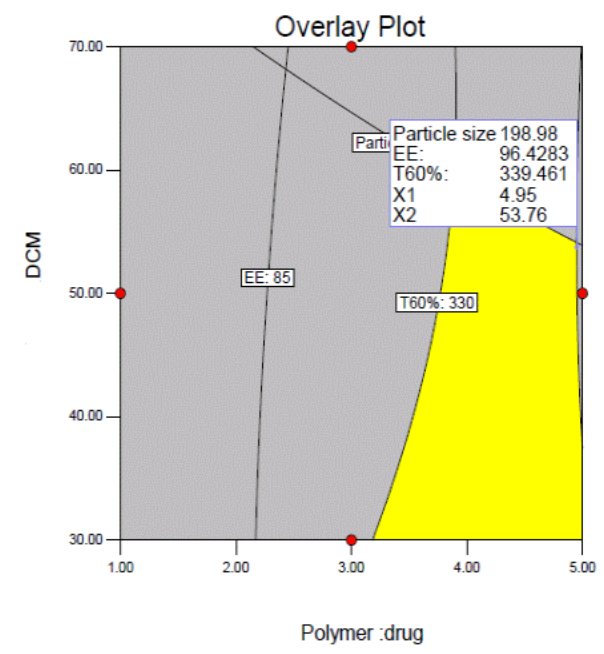

Fig. 4: Design space and optimum setting for optimisation of gastroretantive microspheres

\begin{tabular}{|c|c|c|c|c|c|c|}
\hline Optimal setting & CQA & Predicated & Observed & $\begin{array}{l}\text { Absolute } \\
\text { biases }\end{array}$ & $\begin{array}{l}\text { Relative } \\
\text { biases (\%) }\end{array}$ & Desirability \\
\hline$X_{1}=4.95: 1$ & $Y_{1}(\mu)$ & 198.98 & 203.45 & 4.47 & 2.24 & 0.959 \\
\hline$X_{2}=53.76: 46.24$ & $\mathrm{Y}_{2}(\%)$ & 96.43 & 94.32 & 2.11 & 2.19 & \\
\hline $\mathrm{X}_{3}=2: 5$ & $\mathrm{Y}_{3}(\mathrm{~min})$ & 339.46 & 332.81 & 6.65 & 1.96 & \\
\hline
\end{tabular}

Table 5: Level of parameters, predicate value and experimental result for optimise formulation

\section{Characterization of the optimum gastroretentive microspheres}

\section{Practical yield, entrapment efficiency and floating ability}

The practical yield and entrapment efficiency of the optimum gastro retentive microsphere were found $87.52 \pm 2.91 \%$, and $96.43 \pm 3.14 \%$ respectively. The optimum gastroretantive microsphere showed excellent floating ability up to $90.42 \pm 1.64 \%$

\section{Particle size}

The mean particle size and polydispersibility index (PDI) of optimum gastroretentive microsphere were found $203.34 \pm 4.82 \mu \mathrm{m}$ and 0.65 respectively.

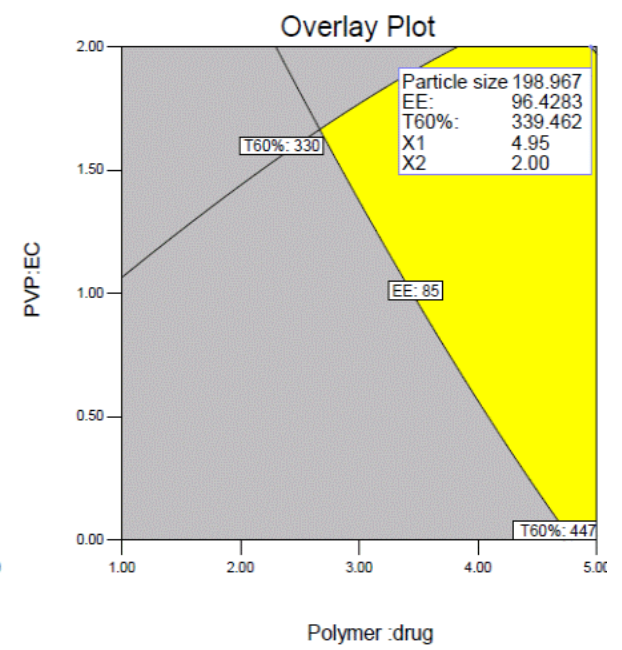

From the plot it is revealed that the T60\% increases with increase in the ratio of polymer and decrease in the ratio of PVP. It is noted that Increasing the amount of polymer in the matrix increases the diffusion path length thereby decreasing drug release [35]. EC is considered as a sustained release polymer due to low water solubility and low permeability and its effect on drug release from macrosphere was influenced by the inclusion of PVP in the matrix. PVP is a water-soluble polymer that can form a passage in the matrix when exposed to the dissolution medium and helps in the diffusion out of the drug. Therefore, the release of PVP ratio increases drug release.

\section{Selection of optimum formulation}

The CQAs acceptance value was set within a desired range to select optimum microsphere formulation and to create a design space for formulation and process parameters. The value of adequate precision greater than 4 revealed that applied model can employ to navigate design space [36] (table 3). The mean particle size was set to $\leq 200 \mu \mathrm{m}$, EE was set to maximize whereas $\mathrm{T}_{60} \%$ was set to $\geq 330$ min. Fig. 4 depicts an overlay plot comprising of two regions, the yellow region referring to the optimal region and the gray area where the response was not in the acceptance criterion [37].

To select optimum formulation, numerical optimization approach was employed and setting for optimum microsphere formulation is shown in table 5 . Lower value of biases and relative biases indicated close agreement with small differences between the observed and targeted value of responses.

\section{Scanning electron microscopy}

The SEM photograph of the optimum gastroretentive microsphere is shown in fig. 5. The SEM photograph revealed that the prepared microspheres were almost spherical in shape and had a rough surface.

\section{In vitro dissolution and drug release kinetic study}

Dissolution study was performed in $0.1 \mathrm{~N} \mathrm{Hcl}$ for 12 h. In vitro drug release profiles of pregabalin from optimum gastroretentive microsphere has been presented in fig. 6 . Table 6 shows the results of fitting of the drug release data for pregablin from the microsphere into various kinetic models. The result shows that pregabalin release found to be best fitted in the Higuchi kinetic model $\left(\mathrm{R}^{2}=0.9891\right)$ and 
diffusional release exponent (n) of Korsmeyer Peppas model was found $0.7243(<0.5)$ indicating grossly non fickian diffusion [38].

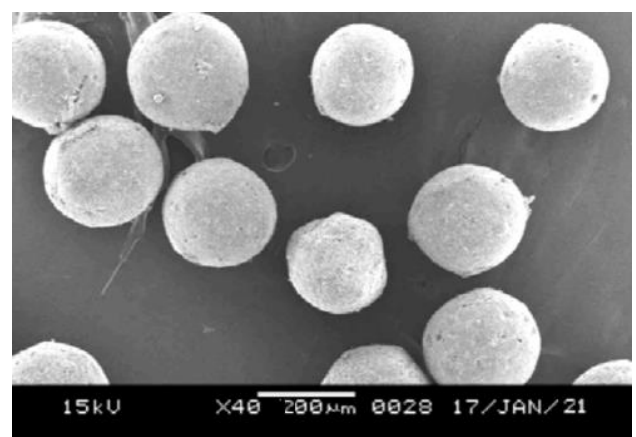

Fig. 5: SEM photograph of optimise microsphere

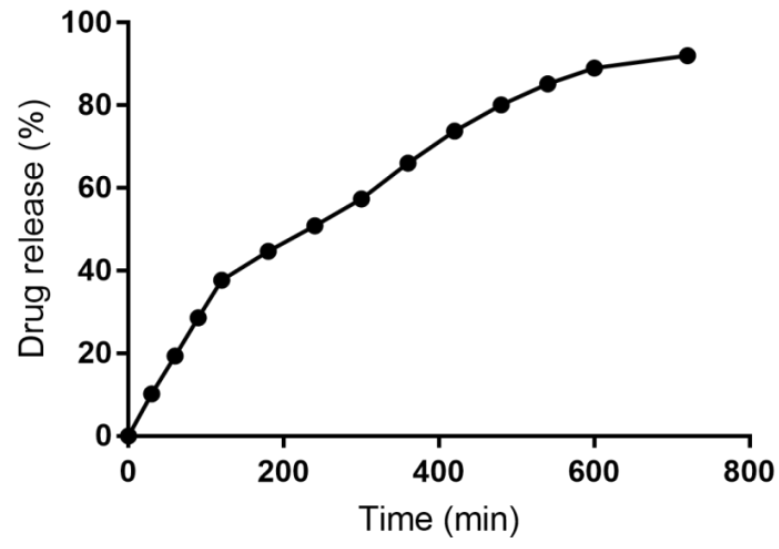

Fig. 6: In vitro drug release of PGB from optimise microsphere
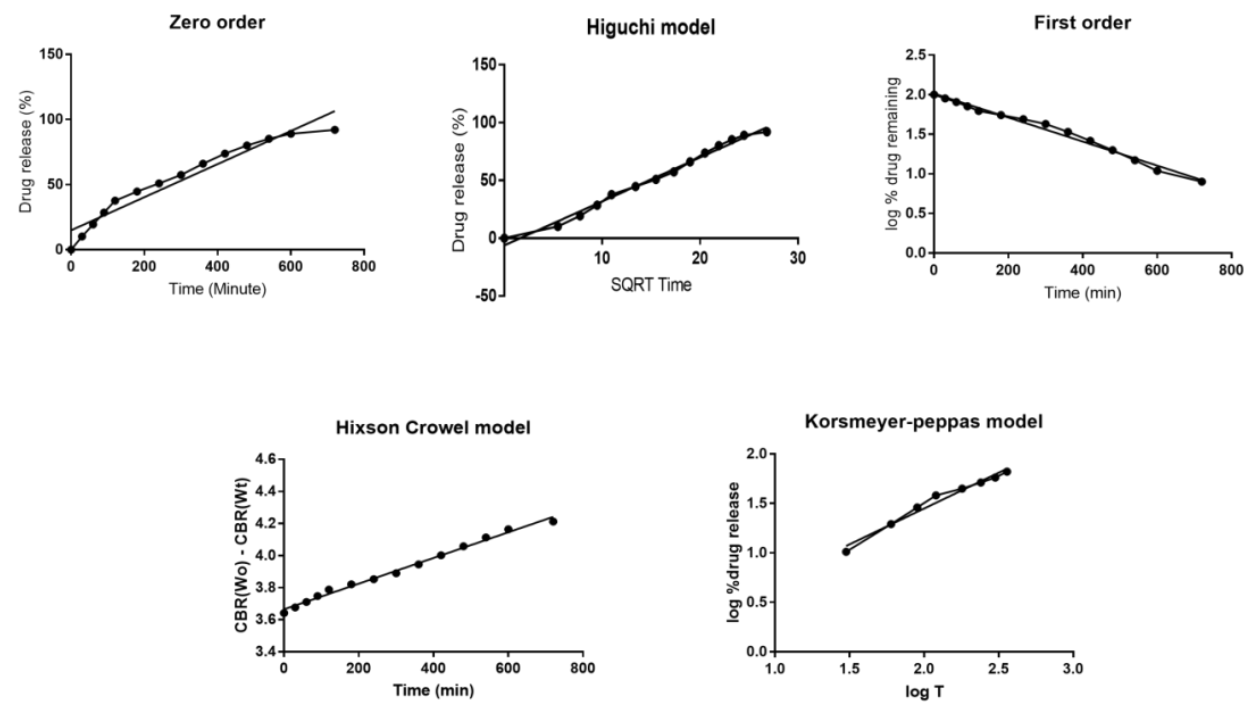

Fig. 7: Different model of drug release kinetic for optimise microsphere

Table 6: Drug release kinetic analysis for optimized microsphere

\begin{tabular}{lllllllll}
\hline Zero order & & \multicolumn{2}{l}{ Higuchi kinetic } & \multicolumn{2}{l}{ First order } & \multicolumn{2}{l}{ Hixson crowel } \\
\hline $\mathbf{R}^{\mathbf{2}}$ & Ko & $\mathbf{R}^{\mathbf{2}}$ & $\mathbf{K}_{\mathbf{h}}$ & $\mathbf{R}^{\mathbf{2}}$ & $\mathbf{K}_{\mathbf{1}}$ & $\mathbf{R}^{\mathbf{2}}$ & $\mathbf{K}_{\mathbf{h c}}$ & $\mathbf{R}^{\mathbf{2}}$ \\
\hline 0.9364 & 0.1271 & 0.9891 & 3.804 & 0.9874 & 0.0034 & 0.962 & 0.0008 & 0.973 \\
\hline
\end{tabular}

\section{CONCLUSION}

In the present study, gastroretantive microsphere of pregabalin was successfully developed using $\mathrm{W} / 0 / 0$ multiple emulsion method. The result pronounces that optimise microsphere exhibited great encapsulation efficiency and excellent floating ability.

\section{FUNDING}

Nil

\section{AUTHORS CONTRIBUTIONS}

All authors have contributed equally.

\section{CONFLICT OF INTERESTS}

The authors declare no conflict of interest, financial or otherwise.

\section{REFERENCES}

1. Viswanathan P, Muralidaran Y, Ragavan G. Challenges in oral drug delivery: a nano-based strategy to overcome. Nanostructures for oral medicine. Elsevier; 2017. p. 173-201.
2. Gupta U, Perumal O. Dendrimers and Its biomedical applications. Natural and Synthetic Biomedical Polymers. Elsevier; 2014. p. 243-57.

3. Bansal S, Beg S, Asthana A, Garg B, Asthana GS, Kapil R, et al. QbD-enabled systematic development of gastroretentive multiple-unit microballoons of itopride hydrochloride. Drug Delivery 2016;23:437-51.

4. Awasthi R, Kulkarni GT. Development of novel gastroretentive drug delivery system of gliclazide: hollow beads. Drug Dev Ind Pharm 2014;40:398-408.

5. Jadi RK, Bomma R, Sellappan V. Development of a new single unit dosage form of propranolol $\mathrm{HCl}$ extended release noneffervescent floating matrix tablets: in vitro and in vivo evaluation. J Appl Pharm Sci 2016;6:112-8.

6. Garg R, Gupta G. Progress in controlled gastroretentive delivery systems. Trop J Pharm Res 2008;7:1055-66.

7. Farooq U, Khan S, Nawaz S, Ranjha NM, Haider MS, Khan MM, et al. Enhanced gastric retention and drug release via the development of novel floating microspheres based on Eudragit E100 and polycaprolactone: synthesis and in vitro evaluation. Des Monomers Polym 2017;20:419-33. 
8. Oth M, Franz M, Timmermans J, Moes A. The bilayer floating capsule: a stomach-directed drug delivery system for misoprostol. Pharm Res 1992;9:298-302.

9. Chen C, Han C-HS, Sweeney M, Cowles VE. Pharmacokinetics, efficacy, and tolerability of a once-daily gastroretentive dosage form of gabapentin for the treatment of postherpetic neuralgia. J Pharm Sci 2013;102:1155-64.

10. Agarwal S, Zamil F, Singh L, Saxena A. Formulation and evaluation of floating beads of diltiazem hcl. Int J Curr Pharm Res 2016;8:38-42.

11. Soppimath KS, Kulkarni AR, Aminabhavi TM. Development of hollow microspheres as floating controlled-release systems for cardiovascular drugs: preparation and release characteristics. Drug Dev Ind Pharm 2001;27:507-15.

12. Kawashima Y, Niwa T, Takeuchi H, Hino T, Itoh Y. Hollow microspheres for use as a floating controlled drug delivery system in the stomach. J Pharm Sci 1992;81:135-40.

13. Adebisi A, Conway BR. Gastroretentive microparticles for drug delivery applications. J Microencapsul 2011;28:689-708.

14. Kesharvani S, Jaiswal PK, Mukerjee A, Singh AK. Formulation and evaluation of metformin hydrochloride loaded floating microspheres. Int J Pharm Pharm Sci 2020;1:74-82.

15. Uchida T, Yoshida K, Goto S. Preparation and characterization of polylactic acid microspheres containing water-soluble dyes using a novel $\mathrm{w} / \mathrm{o} / \mathrm{w}$ emulsion solvent evaporation method. J Microencapsul 1996;13:219-28.

16. Ashjari M, Khoee S, Mahdavian AR. Controlling the morphology and surface property of magnetic/cisplatin-loaded nanocapsules via $\mathrm{W} / \mathrm{O} / \mathrm{W}$ double emulsion method. Colloids Surf Physicochem Eng Aspects 2012;408:87-96.

17. Viswanathan NB, Thomas P, Pandit J, Kulkarni M, Mashelkar R. Preparation of non-porous microspheres with high entrapment efficiency of proteins by a (water-in-oil)-in-oil emulsion technique. J Controlled Release 1999;58:9-20.

18. Aydogan E, Comoglu T, Pehlivanoglu B, Dogan M, Comoglu S, Dogan A, et al. Process and formulation variables of pregabalin microspheres prepared by w/o/o double emulsion solvent diffusion method and their clinical application by animal modeling studies. Drug Dev Ind Pharm 2015;41:1311-20.

19. Tassone DM, Boyce E, Guyer J, Nuzum D. Pregabalin: a novel $\gamma$ aminobutyric acid analogue in the treatment of neuropathic pain, partial-onset seizures, and anxiety disorders. Clin Ther 2007;29:26-48.

20. Kanwar N, Kumar R, Sarwal A, Sinha VR. Preparation and evaluation of floating tablets of pregabalin. Drug Dev Ind Pharm 2016;42:654-60.

21. Beg S, Rahman M, Panda SK, Alharbi KS, Alruwaili NK, Singh PK, et al. Nasal mucoadhesive microspheres of lercanidipine with improved systemic bioavailability and antihypertensive activity. J Pharm Innov 2020;206:1-10.

22. Beg S, Rahman M, Panda S. Pharmaceutical QbD: omnipresence in the product development lifecycle. Eur Pharm Rev 2017;22:58-64.
23. Mennini N, Furlanetto S, Cirri M, Mura P. Quality by design approach for developing chitosan-Ca-alginate microspheres for colon delivery of celecoxib-hydroxypropyl- $\beta$-cyclodextrin-PVP complex. Eur J Pharm Biopharm 2012;80:67-75.

24. Hales D, Vlase L, Porav SA, Bodoki A, Barbu Tudoran L, Achim $\mathrm{M}$, et al. A quality by design $(\mathrm{QbD})$ study on enoxaparin sodium loaded polymeric microspheres for colon-specific delivery. Eur J Pharm Sci 2017;100:249-61.

25. Khanam N, Alam MI, Iqbal QMA, Ali MY, Siddiqui AUR. A review on optinization of drug delivery system with experimental designs. Int J Appl Pharm 2018;10:7-12.

26. Bhoop BS, Raza K, Beg S. Developing "optimized" drug products employing "designed" experiments. Chem Ind Dig 2013;23:70-6.

27. Pandit V, Pai RS, Yadav V, Devi K, Surekha B, Inamdar MN, et al. Pharmacokinetic and pharmacodynamic evaluation of floating microspheres of metformin hydrochloride. Drug Dev Ind Pharm 2013;39:117-27.

28. Gaur PK, Mishra S, Kumar A, Panda BP. Development and optimization of gastroretentive mucoadhesive microspheres of gabapentin by box-behnken design. Artif Cells Nanomed Biotechnol 2014; 42:167-77.

29. Lee JH, Park TG, Choi HK. Development of oral drug delivery system using floating microspheres. J Microencapsul 1999;16:715-29.

30. Phalguna Y, Venkateshwarlu B, Gudas GK, Debnath S. HPMC microspheres of zidovudine for sustained release. Int J Pharm Pharm Sci 2010;2:41-3.

31. Qin C, Wu M, Xu S, Wang X, Shi W, Dong Y, et al. Design and optimization of the gastro-floating sustained-release tablet of pregabalin: in vitro and in vivo evaluation. Int J Pharm 2018;545:37-44.

32. Grzegorzewski P. Statistical tests for comparing pareto charts. Communications Numerical Anal 2012;1-12. DOI:10.5899/2012/cna-00110

33. Mokarram AR. Preparation and in vitro evaluation of indomethacin nanoparticles. Daru 2010;18:185.

34. Gupta R, Prajapati SK, Pattnaik S, Bhardwaj P. Formulation and evaluation of novel stomach specific floating microspheres bearing famotidine for treatment of gastric ulcer and their radiographic study. Asian Pac J Trop Biomed 2014;4:729-35.

35. Dey S, Pramanik S, Malgope A. Formulation and optimization of sustained release stavudine microspheres using response surface methodology. Int Sch Res Notices 2011. DOI:10.5402/2011/627623

36. Bhowmick A, Saha T, Karmoker JR, Reza MS. Design of experiment (doe) approach to prepare, characterize and optimize the gastroretentive mucoadhesive microspheres of repaglinide. Bangladesh Pharm J 2019;22:135-45.

37. Parikh K, Mundada P, Sawant K. Design and optimization of controlled release felbamate tablets by d-optimal mixture design: in vitro-in vivo evaluation. Indian J Pharm Sci 2019;81:71-81.

38. Costa P, Lobo JMS. Modeling and comparison of dissolution profiles. Eur J Pharm Sci 2001;13:123-33. 